\section{Biochemical analysis of serum and synovial fluid in clinically normal young camels (Camelus dromedarius)}

\section{Raida Al-Rukibat, Zuhair Bani Ismail}

Faculty of Veterinary Medicine, Jordan University of Science and Technology, Irbid, Jordan

\begin{abstract}
The objective of this study was to determine the reference range values of various biochemical components in serum and synovial fluid in clinically normal young camels (Camelus dromedarius). One-hundred serum samples and 100 synovial fluid samples were collected from clinically, radiographically and cytologically normal carpal, tarsal and fetlock joints. The concentration of blood urea nitrogen (BUN), creatinine, glucose, sodium, calcium, magnesium, chloride, phosphorus, albumin and the activities of creatine kinase, alanine aminotransfearse, aspartate aminotransferase, lactate dehydrogenase and alkaline phosphatase (ALP) were determined using commercially available kits. The concentration and activities of all measured parameters were significantly lower in the synovial fluid than in the serum except for the ALP and phosphorus, which were similar in both serum and synovial fluids. No significant difference was found in any of the measured biochemical parameters in different joints except in ALP activity, which was higher in the tarsal joint in comparison with the carpal and fetlock joint and the BUN concentration, which was higher in the tarsal joint in comparison with the carpal joint. Baseline values for biochemical components of normal camel synovial fluid and their serum counterparts have been generated. Such data can be used in the clinical investigation of camel's joint diseases.
\end{abstract}

\section{Introduction}

Synovial fluid is a viscous fluid secreted by the synovial lining cells and tendon sheaths. Cytological and chemical analysis of joint fluid provides information for the diagnosis, prognosis, and treatment of various pathological conditions that affect the joint space like inflammatory and infectious synovitis and arthritis. ${ }^{1}$ Reference range values of normal synovial fluid findings were reported for $\operatorname{dog},{ }^{2}$ cat, ${ }^{3}$ horse, $, 4,5$ cattle, ${ }^{6}$ llamas, ${ }^{7}$ and adult camels. ${ }^{8-10}$ Synovial fluid analysis routinely include the following data: volume, color, turbidity, viscosity, total nucleated cell counts, percentage of nucleated cells, total protein values, and specific gravity. ${ }^{11}$ Clinical reports concerning abnormally elevated enzyme concentrations in the synovial fluid of joints affected with different articular diseases in human literature can be found. Increased enzyme activities have been associated with increased phagocytic activities of damaged tissue and/or from peripheral circulation leaking into the inflamed joint.11

Normal synovial fluid of domestic animals contains many enzymes. Alkaline phosphatase (ALP), acid phosphatase, and lactic dehydrogenase (LDH) are present in detectable quantities. The ratios of enzyme levels in the synovial fluid to their levels in the serum in same animal vary according to the animal species under study and also depend on the presence and severity of a particular pathological condition. ${ }^{11-17}$ For example, in equine species, the concentration of LDH isoenzymes in synovial fluid have been reported, and differences between normal and diseased joints have been found. ${ }^{13}$ In this species, LDH levels in the synovial fluid could be of diagnostic value for identifying osteoarthritis. ${ }^{13}$ Furthermore, it was found that the mean activities of ALP, ALT, AST and LDH in arthritic joints in cattle were significantly reduced, whereas the mean aldolase (ALD) activity was increased.14

In camels, few reports can be found in the literature regarding normal biochemical values in synovial fluid from different age groups and different joints. ${ }^{7}$ The purpose of this study was to establish the reference range values of various biochemical components in serum and synovial fluid in clinically normal young camels (Camelus dromedarius).

\section{Materials and Methods}

\section{Animals}

One-hundred, blood and synovial fluid samples from clinically, radiographically and cytologically normal young camels (Camelus dromedarius) ages from 9-12 months were used. Animals were subjected to a complete physical examination for abnormalities in the different body systems to ensure their health. Animals with abnormalities were not included in this study. Animals used in this study were presented to municipality abattoir for meat production. Strict animal welfare practices for slaughtering food animals are enforced by the Government of Jordan in this abattoir.

\section{Collection of the synovial fluid and blood}

Approximately $5 \mathrm{~mL}$ of whole blood were col-
Correspondence: Raida Al-Rukibat, Department of Veterinary Pathology and Public Health, Faculty of Veterinary Medicine, Jordan University of Science and Technology, Irbid, Jordan 22110. Tel. +962.720.1000/22018 - Fax:+962.720.1081 E-mail: ralrukib@just.edu.jo

Key words: synovial, biochemical, glucose, enzymes, joints, camels.

Contributions: the authors contributed equally.

Funding: financial support of this work was provided by the Deanship of Scientific Research, Jordan University of Science and Technology, Irbid, Jordan.

Received for publication: 26 February 2014. Accepted for publication: 2 April 2014.

This work is licensed under a Creative Commons Attribution NonCommercial 3.0 License (CC BYNC 3.0).

(C)Copyright R. Al-Rukibat and Z. Bani Ismail, 2014 Licensee PAGEPress srl, Italy

Veterinary Science Development 2014; 4:5371

doi:10.4081/vsd.2014.5371

lected from each camel from the jugular vein and placed in plain blood tubes. Serum samples were separated by centrifugation of the clotted blood using $5000 \mathrm{G}$ for 10 minutes. Hemolyzed samples were discarded. Serum samples were then preserved at $-20^{\circ} \mathrm{C}$ for further analysis. Immediately after camels were slaughtered, approximately $3 \mathrm{~mL}$ synovial fluid were collected from the right and left carpal, tarsal and fetlock joints as described previously. ${ }^{1}$ Only blood-free samples were used in the analysis.

\section{Laboratory analysis of serum and synovial fluid analysis}

The concentration of blood urea (urease method), creatinine (Jaffe colorimetric-kinetic), glucose (glucose oxidase method), phosphorus (Phophomolybdate. U.V.), albumin (bomo-cresol green method) and the activities of creatinine kinase (NAC.kinetic UV), alanine aminotransferase (LDH-NADH kinetic UV), aspartate aminotransferase (MDH-NADH Kineic UV), lactate dehydrogenase (Pyruvate kinetic), alkaline phosphatase (PNitrophenilphosphate kinetic) were determined. The concentration of sodium, calcium, magnesium and chloride were determined using (Spotchem chemistry analyzer, Arkray factory Inc., Japan).

\section{Statistical analysis}

Data were expressed in mean \pm standard deviation (SD) and ranges. Student's $t$ test was 
used to contrast the effect of joint (carpal, tarsal, and fetlock) on each variable. Variables were also compared between serum and synovial fluid for each parameter. Statistical analyses were performed using Graphpad Prism for windows (Graphpad, San Diego, CA). Differences were considered significant at values of $\mathrm{P}<0.05$.

\section{Results}

The mean \pm SD of various biochemical components in synovial fluid and serum in young camels are presented in Table 1 . The mean \pm SD of various biochemical components in synovial fluid in the carpal, tarsal and fetlock joints in young camels are presented in Table 2 . The concentration and activities of all measured parameters were significantly lower $(\mathrm{P}<0.05)$ in the synovial fluid than in the serum except for the ALP and phosphorus, which were similar in both serum and synovial fluids. No significant difference was found in any of the measured biochemical parameters in different joints except in ALP activity, which was higher in the tarsal joint in comparison with the carpal and fetlock joint and the BUN concentration, which was higher in the tarsal joint in comparison with the carpal joint.

\section{Discussion}

There is a paucity of information on the synovial fluid biochemical parameters of different joints in Dromedarian camels of various age groups. In this study several biochemical values were evaluated in different synovial fluid samples from different joints and their values in synovial fluid were compared to their values in serum. Comparing the values of the studied parameters in the synovial fluid of the carpal, tarsal and fetlock joints showed that there was no significant difference in any of biochemical parameters except for the BUN concentration in the tarsal joints, which was significantly higher than in the carpal joints. The ALP activity in the tarsal joints was significantly higher than the values in the carpal and fetlock joints.

The activities of CK, ALT and LDH in the synovial fluids in our study were lower than values reported for adult camels while the activities ALP and AST were higher than in adult camels. ${ }^{8}$ The concentration of sodium, phosphorus, urea nitrogen and glucose were higher in synovial fluid of young camels in comparison with adult camels. ${ }^{8}$ The concentration of chloride and magnesium were lower in young camels in comparison with adult camels. ${ }^{8}$ The concentration of calcium in young camels was similar to values reported in synovial fluid of adult camel. ${ }^{8}$

Table 1. Mean \pm standard deviation of biochemical parameters of synovial fluid, with comparison to serum values in clinically normal young camels $(\mathbf{n}=\mathbf{2 0 0})$.

\begin{tabular}{lcc} 
Variables & Synovial fluid & Serum \\
BUN (mg/dL) & $16.4 \pm 6.93^{*}$ & $22.9 \pm 8.25$ \\
Creatinine (mg/dL) & $1.1 \pm 0.42^{*}$ & $1.8 \pm 0.15$ \\
\hline Glucose (mg/dL) & $85.5 \pm 28.04^{*}$ & $174.1 \pm 46.34$ \\
CK (U/L) & $12.6 \pm 14.87^{*}$ & $46.4 \pm 3.34$ \\
\hline ALT (U/L) & $35.7 \pm 25.80^{*}$ & $8.3 \pm 0.49$ \\
AST (U/L) & $21.6 \pm 24.18^{*}$ & $162.1 \pm 156.3$ \\
\hline $\mathrm{LDH}(\mathrm{U} / \mathrm{L})$ & $12.7 \pm 14.81^{*}$ & $894.8 \pm 539.4$ \\
$\mathrm{ALP}(\mathrm{U} / \mathrm{L})$ & $116.8 \pm 74.2$ & $134.3 \pm 74.03$ \\
\hline $\mathrm{Na}+(\mathrm{mmol} / \mathrm{L})$ & $152.4 \pm 16.83^{*}$ & $199.3 \pm 40.49$ \\
$\mathrm{Ca}+2(\mathrm{mg} / \mathrm{dL})$ & $4.5 \pm 7.72^{*}$ & $8.4 \pm 1.0$ \\
\hline $\mathrm{Mg}+2(\mathrm{mg} / \mathrm{dLl})$ & $1.4 \pm 0.47^{*}$ & $2.7 \pm 0.63$ \\
$\mathrm{Cl}-(\mathrm{mmol} / \mathrm{L})$ & $117.7 \pm 13.28^{*}$ & $154.7 \pm 33.72$ \\
$\mathrm{P}(\mathrm{mg} / \mathrm{dL})$ & $5 \pm 5.01$ & $5.2 \pm 1.62$ \\
Albumin $(\mathrm{g} / \mathrm{dL})$ & $1.3 \pm 0.55^{*}$ & $4.4 \pm 0.28$
\end{tabular}

*Significantly different when compared to the value of the same parameter in serum $(\mathrm{P}<0.05)$

Table 2. Mean \pm standard deviation of biochemical parameters of synovial fluid from the fetlock, carpal and tarsal joints in clinically normal young camels $(n=100)$.

\begin{tabular}{lccc} 
Variables & Tarsal & Carpal & Fetlock \\
BUN (mg/dL) & $19 \pm 7.4^{*}$ & $12.4 \pm 5.56^{*}$ & $16.6 \pm 6.1$ \\
Creatinine (mg/dL) & $1.1 \pm 0.40$ & $1.1 \pm 0.47$ & $1.0 \pm 0.4$ \\
\hline Glucose $(\mathrm{mg} / \mathrm{dL})$ & $95.8 \pm 29.24$ & $76.1 \pm 24.08$ & $81.8 \pm 26.83$ \\
CK $(\mathrm{U} / \mathrm{L})$ & $13.1 \pm 16.68$ & $14.8 \pm 19.15$ & $10.5 \pm 7.8$ \\
\hline ALT $(\mathrm{U} / \mathrm{L})$ & $38.1 \pm 28.62$ & $34 \pm 25$ & $33.1 \pm 23.6$ \\
AST $(\mathrm{U} / \mathrm{L})$ & $21.6 \pm 30.95$ & $21.7 \pm 20.57$ & $21.5 \pm 18.8$ \\
\hline $\mathrm{LDH}(\mathrm{U} / \mathrm{L})$ & $12.1 \pm 17.2$ & $14.8 \pm 16.51$ & $11.7 \pm 10.5$ \\
$\mathrm{ALP}(\mathrm{U} / \mathrm{L})$ & $153.6 \pm 88.26^{*}$ & $92.7 \pm 51.21^{*}$ & $96.7 \pm 120.7^{*}$ \\
\hline $\mathrm{Na}+(\mathrm{mmol} / \mathrm{L})$ & $155.8 \pm 24.19$ & $152 \pm 8.33$ & $150 \pm 11.2$ \\
$\mathrm{Ca}+2(\mathrm{mg} / \mathrm{dL})$ & $6.1 \pm 12.36$ & $4.4 \pm 1.73$ & $2.9 \pm 1.3$ \\
\hline $\mathrm{Mg}+2(\mathrm{mg} / \mathrm{dL})$ & $1.4 \pm 0.45$ & $1.4 \pm 0.34$ & $1.28 \pm 0.54$ \\
$\mathrm{Cl}-(\mathrm{mmol} / \mathrm{L})$ & $120.6 \pm 18.33$ & $117.4 \pm 10.28$ & $114.9 \pm 7.9$ \\
\hline $\mathrm{P}(\mathrm{mg} / \mathrm{dL})$ & $5.8 \pm 8.13$ & $4.9 \pm 1.41$ & $4.5 \pm 1.19$ \\
$\mathrm{Albumin}(\mathrm{g} / \mathrm{dL})$ & $1.3 \pm 057$ & $1.4 \pm 0.44$ & $1.1 \pm 0.6$
\end{tabular}

${ }^{*}$ Significantly different $(\mathrm{P}<0.05)$.

\section{Conclusions}

In this study, we established a database that could be used as a reference range values for the serum and synovial fluid of the carpal, tarsal and fetlock joints in 9 to 12 months old one-humped camels. This information is important in determining the health status of these joints as macroscopic and radiographic changes as well as culture results may appear too late in the pathologic process.

\section{References}

1. Bani Ismail Z, Al-Rukibat R, Al-Tarazi Y, Al-
Zghoul MB. Synovial fluid analysis and bacterial findings in arthritic joints of juvenile male camel (Camelus dromedarius) calves. J Vet Med A Physiol Pathol Clin Med 2007;54:66-9.

2. Sawyer DC. Synovial fluid analysis of canine joints. J Am Vet Med Assoc 163;143:609-12.

3. Pacchiana PD, Gilley RS, Wallace LJ, et al. Absolute and relative cell counts for synovial fluid from clinically normal shoulder and stifle joints in cats. J Am Vet Med Assoc 2004;225:1866-70.

4. Rose RJ, Frauenfelder HC. Arthrocentesis in the horse. Equine Vet J 1982;14:173-7.

5. Liberg P, Magnusson LE, Schougaard H. Studies on the synovia in healthy horses with particular reference to the protein 
composition. Equine Vet J 1977;9:87-91.

6. Van Pelt RW, Conner GH. Synovial fluid from the normal bovine tarsus. I. Cellular constituents, volume, and gross appearance. Am J Vet Res 1963;24:537-44.

7. Waguespack RW, Belknap EB, Spano JS, et al. Analysis of synovial fluid from clinically normal alpaca and llamas. Am J Vet Res 2002;63:576-8.

8. Nazifi S, Rezakhani A, Gheisari HR. Physical, biochemical and cytologic properties of blood and synovial fluid in clinically normal adult camel (Camelus Dromedarius). J Vet Med A 1998;45:15560.

9. Bani Ismail Z, Al-Rukibat R. Synovial fluid cell counts and total protein concentration in clinically normal fetlock joints of young dromedarian camels. J Vet Med A Physiol Pathol Clin Med 2006;53:263-5.

10. Al-Rukibat RK, Bani Ismail ZA, Al-Zghoul MB. Cytologic analysis of synovial fluid in clinically normal tarsal joints of young camels (Camelus dromedarius). Vet Clin Pathol 2006;35:326-8.

11. Grün E, Panndorf H, Schuhmacher U. Occurrence of various enzymes in synovial fluid of cattle and swine. Arch Exp Veterinarmed 1978;32:907-20.

12. Rejnö S. LDH and LDH isoenzymes of synovial fluid in the horse. Acta Vet Scand 1976;17:178-89.

13. Hurter K, Spreng D, Rytz U, et al. Measurements of C-reactive protein in serum and lactate dehydrogenase in serum and synovial fluid of patients with osteoarthritis. Vet J 2005;169:281-5.

14. Van Pelt RW. Tarsal degenerative joint disease in cattle: blood and synovial fluid changes. Am J Vet Res 1975;36:1009-14.

15. Jovaní V. Synovial fluid analysis. Best practice and research. Clin Rheumatol 2005;19:371-86.

16. Gough MR, Munroe GA, Mayhew G. Urea as a measure of dilution of equine synovial fluid. Equine Vet J 2002;34:76-9.

17. Kraus VB, Huebner JL, Fink C, et al. Urea as a passive transport marker for arthritis biomarker studies. Arthritis Rheum 2002;46:420-7. 